\title{
What Are the Challenges Involved in the Prevention of Depression in Schools?
}

\author{
Dawid Gondek $^{1}$ - Tanya Lereya ${ }^{1}$ \\ Published online: 6 June 2017 \\ (C) The Author(s) 2017. This article is an open access publication
}

\begin{abstract}
Depression is linked with serious social and educational impairments and elevated rates of smoking, substance misuse and obesity among children and adolescents. Due to already existing structures within schools and their important role within the community, they appear to provide an ideal environment to implement preventative strategies against depression. Even though there is a growing evidence base for school-based interventions, it is rarely supportive for their effectiveness. In the current piece, we are exploring potential reasons for a limited success of school-based prevention against depression. We mainly focus on parental mental health as one of the potential moderators of the effectiveness of school-based approaches. We argue that family-oriented approach to mental health provision at schools needs to be taken. We also explore barriers to parental involvement experienced by schools and make recommendations of how these can be mitigated. Finally, the article outlines existing school-based interventions targeting mental health of both pupils and parents.
\end{abstract}

Keywords Mental health $\cdot$ Wellbeing $\cdot$ Intervention · Prevention $\cdot$ Schools

Key Messages

- Prevention of depression in schools is often ineffective

- Parental depression adds highly to the risk of offspring depression

- Preventative efforts in schools need to take a whole family approach to be effective

- Schools need to tackle the mental health stigma and get better at engaging parents in school interventions

Dawid Gondek

dawid.gondek@annafreud.org

1 Evidence Based Practice Unit, Anna Freud National Centre for Children and Families, UCL, London WC1E 6BT, UK

\section{Introduction}

Depression in adolescents is a major risk factor for suicide and it is one of the leading causes of death in this age group (Hawton 2009). Depression is also linked with serious social and educational impairments and elevated rates of smoking, substance misuse and obesity (Fletcher 2008; Keenan-Miller et al. 2007; Hasler et al. 2005). Moreover, there is evidence that half of adults with depression are diagnosed in adolescence, as the average age of onset of depression is 15 years, and less than half of those diagnosed with depression were treated appropriately at the time of diagnosis (Kim-Cohen et al. 2003). Thus, the risk factors of depression ought to be identified and addressed at early age in order to prevent future problems.

It has been emphasised that schools provide an ideal environment to implement prevention strategies against depression. The rising interest in schools acting as a platform for such initiatives has been reflected in growing evidence base for their effectiveness (Corrieri et al. 2014; Calear and Christensen 2010; Werner-Seidler et al. 2017). In this piece, we outline the challenges encountered by schools and specifically focus on whole family approaches as a way forward.

\section{School as an Ideal Setting for Prevention}

Within the recent years, schools have switched their focus to raising healthy children by fostering not only their cognitive but also social and emotional development (Durlak et al. 2011). Hence, schools are increasingly considered as a key setting for support of mental health and wellbeing. Due to prolonged engagement with pupils and the existence of structures that facilitate mental health provision, such as behaviour monitoring, links with external agencies and regular staff- 
parent communication, schools have the tools to play a vital part in screening and supporting children and young people with early depressive symptoms (Stephan et al. 2007). Moreover, schools are often a central hub within the community and they have an important role in referring children and young people to specialist services (Stephan et al. 2007). In fact, schools are often the only community setting where many children are exposed to any behavioural health interventions at all (Stephan et al. 2007).

\section{Evidence for Effectiveness of Preventative Interventions}

The most commonly distinguished broad categories of preventive interventions for depression and other common mental disorders are universal, selective and indicated. Universal interventions aim to support mental health of all pupils, selective approaches target individuals who are at particularly high risk due to exposure to certain risk factors (e.g. children of depressed parents), whereas indicated strategies are designed for pupils who already display symptoms or high-risk behaviours that become the focus of the intervention to prevent further development of the disorder.

Several meta-analyses and systematic reviews investigated the effectiveness of school interventions for preventing depression. They came to similar conclusions, namely school interventions tend to reduce pupils' risk of developing depression immediately post-treatment; however, the effect sizes are small or moderate and the effect tends to decay over time (Horowitz and Garber 2006; Merry et al. 2011). Overall, selective programmes are found to be more effective than universal ones, with the most effective interventions seeming to orient more towards treatment rather than prevention (Horowitz and Garber 2006; Corrieri et al. 2014; WernerSeidler et al. 2017). Stice and colleagues found in their systematic review that larger effects were attained when programmes targeted high-risk individuals, when samples included more females and older adolescents, programmes had shorter duration, included a homework assignment and were delivered by specialists (Stice et al. 2009). Interestingly, content or the focus of the intervention did not have a differential effect. Nonetheless, there is still a persistent heterogeneity in findings. Also, it is unclear why the intervention effects tend to dissipate at follow-up periods greater than 12 months (Horowitz and Garber 2006; Merry et al. 2011; WernerSeidler et al. 2017; Corrieri et al. 2014; Calear and Christensen 2010). More quality research is needed to disentangle the inconsistencies (Horowitz and Garber 2006; Merry et al. 2011; Werner-Seidler et al. 2017; Corrieri et al. 2014; Calear and Christensen 2010). Future studies should include longer follow-ups, comparisons to already existing interventions and scrupulous assessment of the fidelity of the intervention (Horowitz and Garber 2006; Merry et al. 2011; Werner-Seidler et al. 2017; Corrieri et al. 2014; Calear and Christensen 2010).

\section{Parental Depression as a Moderator}

Designing and implementing an effective school-based preventative intervention is a highly challenging task. It is vital to keep in mind that although schools play a fundamental role in pupils' lives, children and young people are also exposed to familial and wider social factors, which are likely to moderate the effectiveness of any school intervention. Particularly, parental depression has been consistently found to be highly associated with the risk of developing depressive and other mental health disorders among children and adolescents (Ramchandani and Murphy 2013; Evans et al. 2005). For instance, it has been demonstrated in a longitudinal study with a rigorous clinical assessment of depressive disorders that recurrent maternal depression is associated with higher rates of psychiatric morbidity in their children (Sellers et al. 2013). Moreover, maternal depression increases risk of developing depressive disorders in their offspring two- to four-fold (Evans et al. 2005). Furthermore, over half of the young people presented to mental health services have parents with current mood disorders (Evans et al. 2005). Hence, parental depression is likely to moderate the effectiveness of preventative interventions.

This hypothesis was supported by a randomised controlled study, which showed that the cognitive behavioural programme was more effective in preventing onset of depression than usual care through the 9-month follow-up period only for those adolescents whose parents were not depressed at the baseline (Garber et al. 2009). As shown by other randomised controlled studies, remission of mother's depression was associated with reduction in behavioural problems and symptoms in their children, whereas relapse was linked with an increase in symptoms (Wickramaratne et al. 2011; Weissman et al. 2014). Improvements in mother's depression was also associated with better parenting during the year after remission and early-remission had favourable effects on children's functioning (Wickramaratne et al. 2011; Weissman et al. 2014). Thus, addressing parental mental health as part of the intervention may be vital. Unfortunately, as pointed out by Corrieri et al. (2014), participation of parents in school interventions is low, thus measuring their impact is highly challenging.

\section{Link Between Parental and Offspring Depression}

The research aiming at explaining how parental depression increases the risk of depression in their children is highly 
limited. Mattejat and Remschmidt (2008), based on the selective literature review, suggested several mechanisms mainly focused on the factors related to the parent-child relationship. For instance, depression may result in alteration of parental behaviours decreasing the quality of parenting. These alterations may take a different form depending on the developmental stage of the child. For example, children in the kindergarten and elementary school years may be affected by reduced verbal communication or mother's difficulty to control children's behaviour and boundaries (Mattejat and Remschmidt 2008). Whereas older children and young people may be forced to take over tasks and responsibilities of their parents ("parentification"), which leads to attenuated rolemodel function of the parents (Mattejat and Remschmidt 2008). There are also risk factors that may affect the child/ young person throughout the entire course of development, for instance, parents with mental health problems are at greater risk of being exposed to sociocultural and socioeconomic risk factors including poverty, inadequate housing, marginal social status and cultural discrimination (Mattejat and Remschmidt 2008).

Notably, some children and young people stay resilient despite parental depression. As shown by a longitudinal study, a subset of young people who maintained high functioning in spite of their parents' illness were characterised by greater understanding of the disorder, having positive relationship with their parents and being focused on accomplishing ageappropriate developmental tasks (Beardslee and Podorefsky 1988). Within the parents, commitment to parenting and relationships were found to have protective effects (Beardslee and Podorefsky 1988).

Thus, it is essential to understand the subjective dimension of the relationship between parental and offspring depression, focusing on both protective and risk factors, particularly on those that are modifiable, such as parenting practices or mental health literacy (Mattejat and Remschmidt 2008). It is also crucial to understand how these multiple factors interact and increase the vulnerability or enhance resilience of young people in order to design an effective preventative intervention (Mattejat and Remschmidt 2008). Nonetheless, there are several barriers preventing parental engagement that need to be addressed to ensure effectiveness of an intervention.

\section{Barriers to Parental Involvement}

There are multiple barriers that may prevent schools from engaging parents into school-based interventions; these may include limited resources such as time and funding or competing priorities. Nonetheless, some of the obstacles are relational or attitudinal in nature. Hence, they are, to certain extent, mutable and could become the focus of future efforts to lay the foundations for effective school interventions.
Firstly, schools overall are not particularly adept at working closely with parents (Stormshak et al. 2016). School personnel lack the understanding of how family factors contribute to the behavioural problems, thus they rarely try to gather information about pupil's home environment, develop closer relationships with parents or engage parents into school-based interventions (Stormshak et al. 2016). Also, as typically the content of school staff's training is limited to working with pupils, they may not have the necessary skills to engage with parents (Stormshak et al. 2016). However, the issue is not limited to individual skills or expertise of school staff but it is rather a more holistic problem, as schools lack organised systems enabling a regular positive interaction with parents (Stormshak et al. 2016).

Secondly, the involvement of parents into school-based interventions may be impeded by the stigma surrounding mental health. Stigma may act differently in various types of preventative interventions. For instance, some parents may distance themselves from people with mental health difficulties, thus they could be unwilling to engage into universal approaches (Rusch and Thornicroft 2004). Whereas, selective or indicated approaches can lead to a feeling of being labelled as "mentally ill" and hindering participation (Rusch and Thornicroft 2004). Parents of children and young people experiencing mental health problems may also be unwilling to seek help due to courtesy stigma, that is, development of stigma by virtue of being associated with someone who is stigmatised (Gale 2006). This may trigger feelings of shame and self-blame, as parents may be afraid of being judged as a "bad" parent. It also impedes the perception of their child as being "perfect" (Gale 2006). Unfortunately, there is currently no effective, evidence-based way to tackle mental health stigma (Mehta et al. 2015). The evidence in the school context is particularly scarce (Griffiths et al. 2014). Nonetheless, the recent cross-sectional survey have indicated that general attitudes to mental health among school staff is positive, which is an optimistic message for future developments of preventative interventions (Patalay et al. 2016).

\section{Involving Families in Preventative Interventions: a Way Forward}

As outlined above, implementation of family-centred interventions is highly challenging due to attitudes surrounding mental health and rather poor relationship between schools and parents. Thus, we argue that schools ought to start with developing communication channels with parents, which would provide school staff with opportunities to share information about school health-related activities, for instance health education classes, and encourage parents to participate in these events (Centers for Disease Control and Prevention 2012). Such events do not need to be limited to depression or 
mental health in general, but may cover a range of health topics with depression among students and impact of parental depression being one of the issues covered. The long-term goal ought to be establishing two-way communications, where schools offer knowledge and support in health-related issues and parents can openly share their concerns or contribute their feedback. This would also help to reduce mental health stigma through education about mental health and normalisation of mental health issues.

Let us consider a hypothetical scenario to illustrate how these communication channels could work in practice. For example, if a given student appears to have emotional problems, both parents and school staff should have a means of approaching one another and openly discuss any risk factors potentially contributing to the problems experiencing by the student, which could also include parental depression or home environment in general. If parental depression was indeed identified as one of the risk factors, both students and parents could receive help through already existing school-based programme or through referral to external services. However, it is crucial that there is a platform available allowing for such interactions to take place at any time, which would be in addition to the regular organised events, in order to mitigate the problem before escalation. For instance, schools could arrange regular face-to-face or online/over the phone drop-in sessions. Having such communication channels built-in in schools' practice would facilitate implementation of interventions with more formal modules aiming at preventing depression among students and taking parental mental health into consideration.

Unfortunately, there is currently a drought of evidence on effective preventative programmes aiming at students as well as parents (Corrieri et al. 2014). However, the Adolescent Transition Program (ATP), which is a family-focused multilevel prevention programme in public middle schools in the USA, provides a few useful examples of intervention components that could be included in preventative approaches against depression. Nonetheless, it is necessary to emphasise that the programme was originally developed as an intervention for adolescents with problem behaviours (Dishion and Kavanagh 2003) and it serves here as an illustrative general framework within which depression-specific content could be implemented. The ATP aims at bridging home and school and ensuring that parents as well as teachers are in communication with one another. Within the programme, families are provided face-to-face meetings with programme implementers during which they learn family management skills, for instance engaging in active listening (Dishion and Kavanaugh 2000). These skills are practiced through group discussions, role-plays and homework activities that are graded to maximise students' and parents' engagement (Dishion and Kavanaugh 2000). In addition, weekly newsletters serve as a reminder of learnt information. In the context of depression, family management skills may have protective effect against the impact of parental depression on the mental health of their offspring. Another feature of the ATP that could be included in the depression preventative programmes is the signposting role that the intervention implementers serve ensuring that families receive adequate services (Dishion and Kavanaugh 2000).

\section{Conclusion}

Depression has a serious impact on social and educational development of young people and in extreme cases may lead to suicide. It has also been consistently found to be associated with mental health problems in the adulthood. Thus, preventative actions should be taken to prevent long-term mental health problems. There is no better setting for early-age preventative interventions than schools, as they play a major role not only in pupils' lives but also in the community in general. Strikingly, we are still awaiting the development and implementation of truly effective school-based practices preventing depression. Unfortunately, too often, the preventative approaches ignore the wider social context in which the child/ young person grows up, which leads to developing fragmented interventions destined to fail.

One of the contextual factors that may be of high importance is parental depression, which has been found to be highly associated with depression in their offspring and there is evidence that it moderates effectiveness of the preventative interventions. Thus, it is time to take a holistic, familycentred approach, to prevent depression in childhood/adolescence. Nonetheless, before this can happen, we need to address some crucial challenges related to school-family interaction, such as building school-family relationships, providing more staff training, and tackling mental health stigma.

Interventions, such as the Adolescent Transition Program, target both students and parents and can provide foundations for preventative interventions against depression. Hence, our efforts ought to be directed at building an evidence base for such interventions and spread good practice while keeping in mind unique contextual factors characterised each school.

\section{Compliance with Ethical Standards}

Conflict of Interest The authors declare that they have no conflict of interest.

Funding This study was not supported by any funding.

Ethical Approval This article does not contain any studies with human participants performed by any of the authors. 
Open Access This article is distributed under the terms of the Creative Commons Attribution 4.0 International License (http:// creativecommons.org/licenses/by/4.0/), which permits unrestricted use, distribution, and reproduction in any medium, provided you give appropriate credit to the original author(s) and the source, provide a link to the Creative Commons license, and indicate if changes were made.

\section{References}

Beardslee, W. R., \& Podorefsky, D. (1988). Resilient adolescents whose parents have serious affective and other psychiatric-disorders-importance of self-understanding and relationships. American Journal of Psychiatry, 145(1), 63-69.

Calear, A. L., \& Christensen, H. (2010). Systematic review of schoolbased prevention and early intervention programs for depression. Journal of Adolescence, 33(3), 429-438. doi:10.1016/j. adolescence.2009.07.004.

Centers for Disease Control and Prevention. (2012). Parent engagement: strategies for involving parents in school health. Atlanta, GA: U.S. Department of Health and Human Services.

Corrieri, S., Heider, D., Conrad, I., Blume, A., Konig, H. H., \& RiedelHeller, S. G. (2014). School-based prevention programs for depression and anxiety in adolescence: a systematic review. Health Promotion International, 29(3), 427-441. doi:10.1093/heapro/ dat001.

Dishion, T. J., \& Kavanagh, K. (2000). A multilevel approach to familycentered prevention in schools: process and outcome. Addictive Behaviors, 25(6), 899-911. doi:10.1016/S0306-4603(00)00

Dishion, T. J., Kavanagh, K. (2003). Intervening with adolescent problem behavior: A family-centered approach. New York: Guilford.

Durlak, J. A., Weissberg, R. P., Dymnicki, A. B., Taylor, R. D., \& Schellinger, K. B. (2011). The impact of enhancing students' social and emotional learning: a meta-analysis of school-based universal interventions. Child Development, 82(1), 405-432. doi:10.1111/j. 1467-8624.2010.01564.x.

Evans, D. L., Beardslee, W., Biederman, J., Brent, D., Charney, D., Coyle, J., et al. (2005). Defining depression and bipolar disorder. In D. L. Evans, E. B. Foa, R. E. Gur, H. Hendin, C. P. O'Brien, M. E. P. Seligman, et al. (Eds.), Treating and preventing adolescent mental health disorders: What we know and what we don't know (pp. 4-27). New York: Oxford University Press.

Fletcher, J. M. (2008). Adolescent depression: diagnosis, treatment, and educational attainment. Health Economics, 17(11), 1215-1235. doi: 10.1002/Hec. 1319 .

Gale, F. (2006). Children's and parents'/carers' perceptions of mental health and stigma., University of Leicester, Unpublished PhD thesis.

Garber, J., Clarke, G. N., Weersing, V. R., Beardslee, W. R., Brent, D. A., Gladstone, T. R. G., et al. (2009). Prevention of depression in at-risk adolescents a randomized controlled trial. Jama-Journal of the American Medical Association, 301(21), 2215-2224.

Griffiths, K. M., Carron-Arthur, B., Parsons, A., \& Reid, R. (2014). Effectiveness of programs for reducing the stigma associated with mental disorders. A meta-analysis of randomized controlled trials. World Psychiatry, 13(2), 161-175. doi:10.1002/wps.20129.

Hasler, G., Pine, D. S., Kleinbaum, D. G., Gamma, A., Luckenbaugh, D., Ajdacic, V., et al. (2005). Depressive symptoms during childhood and adult obesity: the Zurich Cohort Study. Molecular Psychiatry, 10(9), 842-850. doi:10.1038/sj.mp.4001671.

Hawton, K. v. H., K. (2009). Suicide. The Lancet, 373(9672), 1372 1381. doi:10.1016/S0140-6736(09)60372-X.

Horowitz, J. L., \& Garber, J. (2006). The prevention of depressive symptoms in children and adolescents: a meta-analytic review. Journal of
Consulting and Clinical Psychology, 74(3), 401-415. doi:10.1037/ 0022-006X.74.3.401.

Keenan-Miller, D., Hammen, C. L., \& Brennan, P. A. (2007). Health outcomes related to early adolescent depression. Journal of Adolescent Health, 41(3), 256-262. doi:10.1016/j.jadohealth.2007. 03.015.

Kim-Cohen, J., Caspi, A., Moffitt, T. E., Harrington, H., Milne, B. J., \& Poulton, R. (2003). Social prior juvenile diagnoses in adults with mental disorder. Archives of General Psychiatry, 60, 709-717.

Mattejat, F., \& Remschmidt, H. (2008). The children of mentally ill parents. Deutsches Arzteblatt International, 105(23), 413-418. doi:10. 3238/arztebl.2008.413.

Mehta, N., Clement, S., Marcus, E., Stona, A. C., Bezborodovs, N., Evans-Lacko, S., et al. (2015). Evidence for effective interventions to reduce mental health-related stigma and discrimination in the medium and long term: systematic review. The British Journal of Psychiatry, 207(5), 377-384. doi:10.1192/bjp.bp.114.151944.

Merry, S. N., Hetrick, S. E., Cox, G. R., Brudevold-Iversen, T., Bir, J. J., \& McDowell, H. (2011). Psychological and educational interventions for preventing depression in children and adolescents. Cochrane Database of Systematic Reviews, 12. doi:10.1002/ 14651858.Cd003380.Pub3.

Patalay, P., Giese, L., Stankovic, M., Curtin, C., Moltrecht, B., \& Gondek, G. (2016). Mental health provision in schools: priority, facilitators and barriers in 10 European countries. Child and Adolescent Mental Health. doi:10.1111/camh.12160.

Ramchandani, P. G., \& Murphy, S. E. (2013). Parental depression and the challenge of preventing mental illness in children. British Journal of Psychiatry, 202(2), 84-85. doi:10.1192/bjp.bp.112.115659.

Rusch, N., \& Thornicroft, G. (2004). Does stigma impair prevention of mental disorders? The British Journal of Psychiatry, 204, 249-251. doi:10.1192/bjp.bp.113.131961.

Sellers, R., Collishaw, S., Rice, F., Thapar, A. K., Potter, R., Mars, B., et al. (2013). Risk of psychopathology in adolescent offspring of mothers with psychopathology and recurrent depression. British Journal of Psychiatry, 202(2), 108-114. doi:10.1192/bjp.bp.111.104984.

Stephan, S. H., Weist, M., Kataoka, S., Adelsheim, S., \& Mills, C. (2007). Transformation of children's mental health services: the role of school mental health. Psychiatric Services, 58(10), 1330-1338. doi:10.1176/appi.ps.58.10.1330.

Stice, E., Shaw, H., Bohon, C., Marti, C. N., \& Rohde, P. (2009). A metaanalytic review of depression prevention programs for children and adolescents: factors that predict magnitude of intervention effects. Journal of Consulting and Clinical Psychology, 77(3), 486-503. doi:10.1037/a0015168.

Stormshak, E. A., Brown, K. L., Moore, K. J., Dishion, T., Seeley, J., \& Smolkowski, K. (2016). Going to scale with family-centered, school-based interventions: challenges and future directions. In M. S. Sheridan \& E. Moorman Kim (Eds.), Family-school partnerships in context (pp. 25-44). Cham: Springer International Publishing.

Weissman, M. M., Wickramaratne, P., Pilowsky, D. J., Poh, E., Hernandez, M., Batten, L. A., et al. (2014). The effects on children of depressed mothers' remission and relapse over 9 months. Psychological Medicine, 44(13), 2811-2824. doi:10.1017/ S003329171400021x.

Werner-Seidler, A., Perry, Y., Calear, A. L., Newby, J. M., \& Christensen, H. (2017). School-based depression and anxiety prevention programs for young people: a systematic review and meta-analysis. Clinical Psychology Review, 51, 30-47. doi:10.1016/j.cpr.2016.10.005.

Wickramaratne, P., Gameroff, M. J., Pilowsky, D. J., Hughes, C. W., Garber, J., Malloy, E., et al. (2011). Children of depressed mothers 1 year after remission of maternal depression: findings from the STAR*D-child study. American Journal of Psychiatry, 168(6), 593-602. doi:10.1176/appi.ajp.2010.10010032. 
Dawid Gondek is currently a $\mathrm{PhD}$ Candidate at the Centre for Longitudinal studies (Institute of Education/University College London). He worked previously as a researcher at the Anna Freud National Centre for - Children \& Families /University College London, coordinating evaluation of a nationwide project entitled Situation Awareness for Everyone. The project aimed at improving patients safety on paediatric wards through increasing situation awareness among staff. $\mathrm{He}$ has also been involved in research exploring potential advancements to mental health care, as guided by person-centered approach, and investigating current mental health provision at schools across Europe.

Dr Tanya Lereya is a research fellow at the Evidence Based Practice Unit (EBPU). Tanya completed her PhD at the University of Warwick which investigated the range of risk factors for bullying and the long lasting effects into adulthood. In particular, she focused on the impact of bullying victimisation on adolescents' well-being and how experiences of bullying, as early as primary school, affect long-term psychological and social functioning. Following her $\mathrm{PhD}$, she worked as a research fellow at the University of Warwick before joining the Evidence Based Practice Unit (EBPU) based across University College London and the Anna Freud National Centre for Children and Families. Her current research focuses on social, emotional and educational outcomes of children; and the effectiveness of interventions to improve children's mental health and well-being in schools. She is particularly interested in the relationship between social, emotional and educational outcomes for children and identifying protective factors that help children in the face of adversity. 